\title{
MARCHA DE ABSORÇÃO DE MACRONUTRIENTES NA CULTURA DO GIRASSOL ${ }^{(1)}$
}

\author{
Luiz Henrique Saes Zobiole ${ }^{(2)}$, César de Castro $^{(3)}$, Fabio Alvares de \\ Oliveira $^{(3)}$ \& Adilson de Oliveira Junior ${ }^{(3)}$
}

\begin{abstract}
RESUMO
Este trabalho teve como objetivo estabelecer curvas de acúmulo de macronutrientes na cultura do girassol. Para isso, foi instalado um experimento em campo sobre Latossolo Vermelho distroférrico de textura muito argilosa, localizado na fazenda experimental da Embrapa Soja, em Londrina/PR. As parcelas foram constituídas de 14 linhas com $25 \mathrm{~m}$ de comprimento cada e espaçamento entrelinhas de $0,70 \mathrm{~m}$, resultando em área total de $245 \mathrm{~m}^{2}$. Cada parcela foi repetida quatro vezes. A adubação de semeadura foi de $300 \mathrm{~kg} \mathrm{ha}^{-1}$ da fórmula 5-20-20, aplicada a lanço, antes do plantio. A adubação de cobertura foi parcelada em duas aplicações: 25 e $1 \mathrm{~kg} \mathrm{ha}^{-1}$ de $\mathrm{N}$ e $\mathrm{B}$, respectivamente, sendo a primeira aos 21 e a segunda aos 35 dias após a semeadura. O híbrido utilizado foi o BRS-191, e a densidade final de plantas foi de 40.000 plantas ha-1. Amostras de plantas foram coletadas em intervalos de 14 dias após a emergência e separadas em pecíolos, folhas, caules e, quando existentes, em capítulo e em aquênios. Após secagem, cada parte da planta foi pesada e moída para, em seguida, determinarem-se os teores de N, P, K, Ca, Mg e S. A partir desses nutrientes e da matéria seca de cada parte da planta, foram obtidas as curvas de acúmulo. Verificou-se que, para obtenção de produtividades superiores a $3.000 \mathrm{~kg} \mathrm{ha}^{-1}$, o híbrido BRS 191 extrai aproximadamente 150, 24, 286, 116, 42 e $24 \mathrm{~kg} \mathrm{ha}^{-1}$ de $\mathrm{N}, \mathrm{P}, \mathrm{K}, \mathrm{Ca}, \mathrm{Mg}$ e S, respectivamente, resultando na seguinte ordem de extração: $\mathrm{K}>\mathrm{N}>\mathrm{Ca}>\mathrm{Mg}>\mathrm{P}=$ S. Em relação à exportação, a ordem dos nutrientes foi a seguinte: $N>P=K>M g=$ $\mathrm{S}>\mathrm{Ca}$. Portanto, atenção especial deve ser dada à manutenção da adequada disponibilidade de $\mathrm{N}, \mathrm{K}$ e Ca, devido à alta demanda da cultura por esses nutrientes.
\end{abstract}

Termos de indexação: Helianthus annuus, crescimento, acúmulo.

\footnotetext{
(1) Recebido para publicação em abril de 2009 e aprovado em janeiro de 2010.

(2) Doutorando do Programa de Pós-Graduação em Agronomia, área de concentração em Proteção de Plantas, Universidade Estadual de Maringá - PGA/UEM. Av. Colombo 5790, CEP 87020-900 Maringá (PR). Bolsista do CNPq. E-mail: lhzobiole@uol.com.br

(3) Pesquisador da Embrapa Soja, Caixa Postal 231, CEP 86001-970 Londrina (PR). E-mails: ccastro@cnpso.embrapa.br; falvares@cnpso.embrapa.br; adilson@cnpso.embrapa.br
} 


\title{
SUMARRY: MACRONUTRIENT UPTAKE OF SUNFLOWER (Helianthus
}

annuus $L$.)

\begin{abstract}
This study aimed to establish curves of macronutrient accumulation in sunflower. The experiment was conducted in the field on a Typic Hapludox, at the experimental station of Embrapa Soja in Londrina, State of Paraná. The plots consisted of $1425 \mathrm{~m}$ long rows spaced $0.70 \mathrm{~m}$ apart, resulting in a total area of $245 \mathrm{~m}^{2}$, with four replications. Prior to sowing a fertilization seeding of $300 \mathrm{~kg} \mathrm{ha}^{-1}$ of 05-20-20 NPK fertilizer was applied. Fertilization was split in two applications of $25+1 \mathrm{~kg} \mathrm{ha}^{-1} \mathrm{~N}$ and $\mathrm{B}$, which were applied 21 and 35 days after sowing, respectively. The hybrid BRS 191 and a final plant density of 40,000 plants ha ${ }^{-1}$ were used. Plant samples were collected every two weeks after emergence and separated in the different parts (petioles, leaves, stems and, when applicable, capitula and achenes). After drying, each plant part was weighed and ground to determine the $N, P, K, C a, M g$, and $S$ content. From the contents of these nutrients and dry mass of each plant, the accumulation curve was obtained. It was found that for yields $>3,000 \mathrm{~kg} \mathrm{ha}^{-1}$, BRS 191 extracted about 150, 24, 286, 116, 42, and $24 \mathrm{~kg} \mathrm{ha} \mathrm{s}^{-1}$ of $\mathrm{N}, \mathrm{P}, \mathrm{K}, \mathrm{Ca}, \mathrm{Mg}$, and $\mathrm{S}$, respectively, in the following order of extraction: $K>N>C a>P=S$. In addition to the relation to exportation, the nutrient order was: $N>P=K>S=M g>C a$. Therefore, special attention should be paid to the maintenance of an adequate supply of $N, K$ and $C a$, due to the high demand of sunflower.
\end{abstract}

Index terms: Helianthus annuus, growth, accumulation.

\section{INTRODUÇÃO}

O girassol (Helianthus annuus L.) é uma dicotiledônea anual e originária da América do Norte. No Brasil, seu cultivo ocupa área de aproximadamente 100.000 ha, concentrado, principalmente, na região dos Cerrados (CONAB, 2008). É uma planta que se adapta bem a diversas condições edafoclimáticas, caracterizando-se pela tolerância a baixas temperaturas na fase inicial de desenvolvimento e pela relativa resistência a déficits hídricos. Pode ser cultivada em todas as regiões do País, pois o rendimento é pouco influenciado pelas latitudes e altitudes, assim como pelo fotoperíodo, o que facilita a expansão do cultivo no Brasil (Castro et al., 1996; Castro \& Farias, 2005).

O grande interesse mundial pela cultura do girassol está associado à excelente qualidade do óleo, rico em ácidos graxos poli-insaturados, principalmente o ácido linoleico (66 \%) (Mandarino, 1992). Além da qualidade, o teor de óleo nas sementes é alto, proporcionando assim maior rendimento na produção de óleo por hectare se comparado com o da cultura da soja, por exemplo (Lazzarotto et al., 2005). Nos últimos anos, a demanda por óleos de origem vegetal vem aumentando significativamente, impulsionada pela busca de alternativas às energias não renováveis. Nesse sentido, a cultura do girassol pode ser adotada como opção viável, pois, além do teor e qualidade do óleo, ela pode ser produzida em larga escala e com alto rendimento. Entretanto, Dall'Agnol et al. (2005) mencionam que ainda falta ao agricultor brasileiro experiência e tradição, bem como capacitação da assistência técnica, para maior expansão e rendimento da cultura do girassol no Brasil.
O crescimento e desenvolvimento da planta de girassol é dividido em duas fases: vegetativa e reprodutiva. A fase vegetativa refere-se ao período da germinação até o período do broto floral, sendo dividida em Ve (emergência) e Vi, que se caracteriza pelo aparecimento de folhas verdadeiras e é definido pelo número de folhas com no mínimo $4 \mathrm{~cm}$ de comprimento (V1, V2, V3, V4 e Vn). A fase reprodutiva, por sua vez, está organizada da seguinte forma: R1 - a inflorescência circundada pela bráctea imatura tornase visível; R2 e R3 - fases relacionadas à elongação do internódio imediatamente abaixo da base da inflorescência; R4 e R5 - fases relacionadas a abertura da inflorescência e início da antese, respectivamente; R6 - a antese está completa e as flores liguladas perdem a turgidez; R7 e R8 - fases relacionadas ao enchimento de aquênios; e R9 - maturação fisiológica (Schneiter \& Miller, 1981; Connor \& Hall, 1997; Castro \& Farias, 2005).

A quantidade de nutrientes acumulada e exportada pelos grãos é importante para o manejo da adubação. Existem poucas informações sobre nutrição mineral de girassol no Brasil, principalmente em condições de campo; os trabalhos de marcha de absorção existentes foram desenvolvidos na década de 1980 (Sfredo et al., 1983a,b), com híbridos de características genotípicas diferentes das atuais.

Portanto, conhecer os aspectos relacionados à nutrição mineral do girassol é fundamental para ter sucesso no seu cultivo; entre esses aspectos, a marcha de absorção dos nutrientes é essencial para definir as estratégias de adubação da cultura. Assim, este trabalho teve como objetivo estabelecer as curvas de acúmulo de $\mathrm{N}, \mathrm{P}, \mathrm{K}, \mathrm{Ca}, \mathrm{Mg}$ e $\mathrm{S}$ e, a partir dessas 
informações, verificar a ordem de extração, assim como os órgãos e os estádios de desenvolvimento em que ocorre o maior acúmulo.

\section{MATERIAL E MÉTODOS}

O experimento foi instalado em 3/10/2001 na área experimental da Embrapa Soja, Londrina - PR, situada na latitude de $23^{\circ} 23^{\prime} \mathrm{S}$, longitude de $51^{\circ} 11^{\prime} \mathrm{W}$ e altitude de $565 \mathrm{~m}$. O solo da área experimental foi classificado como Latossolo Vermelho distroférrico (Embrapa, 2006), com as seguintes características da camada arável $(0-20 \mathrm{~cm}): 750 \mathrm{~g} \mathrm{~kg}^{-1}$ de argila; $\mathrm{pH} \mathrm{CaCl}_{2}$ de 5,2; $17 \mathrm{mg} \mathrm{dm}^{-3}$ de $\mathrm{P}$ (Mehlich-1); $0,45 \mathrm{cmol}_{\mathrm{c}} \mathrm{dm}^{-3}$ de $\mathrm{K}^{+} ; 5,0 \mathrm{cmol}_{\mathrm{c}} \mathrm{dm}^{-3} \mathrm{de} \mathrm{Ca}^{2+}$; $1,9 \mathrm{cmol}_{\mathrm{c}} \mathrm{dm}^{-3}$ de $\mathrm{Mg}^{2+} ; 3,4 \mathrm{cmol}_{\mathrm{c}} \mathrm{dm}^{-3} \mathrm{de} \mathrm{H}+\mathrm{Al}$; e $17,6 \mathrm{~g} \mathrm{dm}^{-3}$ de $\mathrm{C}$ orgânico. A caracterização química foi realizada de acordo com os procedimentos propostos em Embrapa (1999).

A adubação foi de $300 \mathrm{~kg} \mathrm{ha}^{-1}$ da fórmula 5-2020, aplicada a lanço, antes da semeadura. A adubação de cobertura foi parcelada em duas aplicações: 25 e $1 \mathrm{~kg} \mathrm{ha}^{-1}$ de $\mathrm{N}$ e B, respectivamente, sendo a primeira aos 21 e a segunda aos 35 dias após a semeadura. O experimento foi delineado com quatro parcelas de $245 \mathrm{~m}^{2}$ cada, com 14 linhas de $25 \mathrm{~m}$ de comprimento e espaçamento de $0,70 \mathrm{~m}$. O híbrido utilizado foi o BRS 191, com densidade final de plantas de 40.000 plantas ha ${ }^{-1}$. Foram realizadas sete coletas, com intervalos de 14 dias entre elas. Na primeira, aos 14 dias após a emergência (DAE), 25 plantas foram cortadas rente à superfície do solo, separando-se as amostras em pecíolos, folhas e caules. A partir da segunda coleta, o número de plantas amostradas foi reduzido para quatro, procedendo-se à separação em pecíolos, folhas e caules e, quando existentes, em capítulos e aquênios.

As diversas partes das plantas foram lavadas com água deionizada e secas em estufa com circulação forçada de ar a $65{ }^{\circ} \mathrm{C}$; em seguida, as amostras foram moídas em moinho tipo Wiley. A análise química das amostras foi realizada no Laboratório de Análises Químicas de Solo e de Tecido Vegetal da Embrapa Soja, segundo método descrito por Sarruge \& Haag (1974), sendo digestão sulfúrica para N e nítricoperclórica para $\mathrm{P}, \mathrm{K}, \mathrm{Ca}, \mathrm{Mg}$ e S. A determinação do $\mathrm{N}$ foi feita pelo método de Indofenol (Miyazawa et al., 1992). O P foi determinado por colorimetria de vanadato-molibdato; o K, por fotometria de chama; o Ca e o Mg, por espectrofotometria de absorção atômica; e o S, por turbidimetria.

O ajuste para o acúmulo dos nutrientes, em cada parte da planta, em função do tempo foi realizado por meio de modelos de regressão, utilizando-se o modelo Gaussian com três parâmetros, descrito a partir da seguinte equação genérica:

$$
\hat{y}=a e^{\left[-0,5\left(\frac{x-x_{0}}{b}\right)^{2}\right]}
$$

em que: $\hat{y}=$ acúmulo de nutrientes; $\mathrm{a}=$ corresponde ao valor de máximo acúmulo; $\mathrm{x}_{0}=$ corresponde ao valor de $\mathrm{x}$, em DAE, que proporciona o máximo em $\hat{y} ; \mathrm{e} b=$ corresponde à amplitude no valor de $\mathrm{x}$, em DAE, entre o ponto de inflexão e o ponto de máximo.

Assim, a partir do modelo ajustado foi possível determinar, com exatidão, o valor do ponto de inflexão (PI) na curva da seguinte forma:

$$
\mathrm{PI}=\mathrm{x}_{0}-\mathrm{b}
$$

Matematicamente, o PI corresponde ao valor de x em que a curvatura do modelo ajustado muda de sinal; na prática, isso corresponde ao valor de x, em DAE, em que a taxa de acúmulo diário, ainda que positiva, passa a decrescer.

\section{RESULTADOS E DISCUSSÃO}

\section{Produção de matéria seca e concentração de nutrientes}

O incremento de matéria seca (MS) foi lento até o estádio de desenvolvimento V16, que ocorreu aos 28 DAE, aproximadamente (Figura 1). A partir do estádio R1, a produção de MS aumentou de forma acentuada, atingindo valor máximo aos 89 DAE, com 237,46 g/planta de MS total (Quadro 1). Resultados semelhantes foram encontrados por Sfredo et al. (1984), com crescimento lento até os 42 DAE e máximo acúmulo entre 84 e 88 DAE.

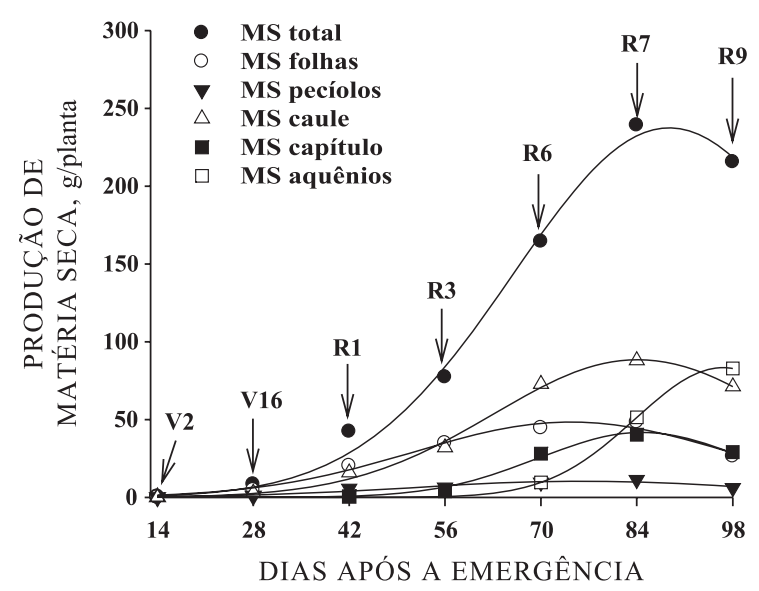

Figura 1. Acúmulo de matéria seca total das respectivas partes da planta amostradas, em função do tempo. 
Quadro 1. Estimativas dos parâmetros dos modelos ajustados para o acúmulo de matéria seca total e de aquênios em função do tempo e os respectivos valores do ponto de inflexão (PI)

\begin{tabular}{|c|c|c|c|c|c|}
\hline \multirow{2}{*}{$\begin{array}{c}\text { Variáveis } \\
\text { dependentes }\end{array}$} & \multicolumn{3}{|c|}{ Estimativa dos parâmetros do modelo ajustado ${ }^{(2)}$} & \multirow{2}{*}{$\begin{array}{c}P I \\
\left(X_{0}-b\right)\end{array}$} & \multirow{2}{*}{$\mathbf{R}^{2}$} \\
\hline & $\mathbf{a}$ & $\mathbf{X}_{0}$ & b & & \\
\hline & g/planta & \multicolumn{2}{|c|}{ — dias após a emergência —_ } & & \\
\hline MS total ${ }^{(1)}$ & $237,46^{* *}$ & $88,81^{* *}$ & $22,42^{* *}$ & 66 & 0,99 \\
\hline MS aquênio & $83,36^{* *}$ & $96,59^{* *}$ & $12,79^{* *}$ & 84 & 0,99 \\
\hline
\end{tabular}

(1) Somatório da MS das folhas, dos pecíolos, do caule, do capítulo e dos aquênios. ${ }^{(2)}$ a: corresponde ao valor de máximo acúmulo; $\mathrm{x}_{0}$ : corresponde ao valor de $\mathrm{x}$, em DAE, que proporciona o máximo em $\hat{\mathrm{y}}$; b: corresponde à amplitude no valor de $\mathrm{x}$, em DAE, entre o ponto de inflexão e o ponto de máximo. ${ }^{* *}$ : significativo a $1 \%$ pelo teste t.

É importante enfatizar que o híbrido utilizado apresentou ciclo de desenvolvimento de 98 dias até a maturação fisiológica (R9), ou seja, trata-se de um material de ciclo semiprecoce e com alta taxa de crescimento e acúmulo de MS a partir da fase reprodutiva, tendo em vista que entre os $42 \mathrm{DAE}(\mathrm{R} 1)$ e 89 DAE (R8) ocorreu o acúmulo de $89 \%$ da matéria seca total produzida, correspondendo a uma taxa diária média de produção de MS de 4,44 g/planta dia.

A produção de aquênios, por sua vez, teve início a partir dos 70 DAE (estádio R7), com acúmulo máximo de 83,36 g/planta aos 96 DAE (Quadro 1 e Figura 1). Com base na massa de aquênios e na densidade de plantas, a produtividade estimada de MS total (incluindo os aquênios) e a MS de aquênios foram, respectivamente, de 9.498 e $3.334 \mathrm{~kg} \mathrm{ha}^{-1}$, com índice de colheita aparente ${ }^{(4)}$ de 0,35 . Logo, o valor obtido está dentro da faixa indicada por Merrien (1992), que é de 0,25 a 0,35 .

As concentrações médias de nutrientes nas folhas, pecíolos, caule, capítulo e aquênios, em cada coleta, podem ser visualizadas no quadro 2. Exceção feita para o K, observaram-se maiores concentrações de nutrientes nas folhas, sendo este órgão a principal fonte de redistribuição dos nutrientes móveis na planta (N e $\mathrm{P}$, principalmente) durante os estádios relacionados ao enchimento de aquênios (R7 e R8). As maiores concentrações de K, por sua vez, foram observadas nos pecíolos e no caule. Entretanto, a redistribuição de K ocorre de forma mais acentuada em direção ao capítulo (estádio R9, 39,4 $\mathrm{g} \mathrm{kg}^{-1}$ ) e não para os aquênios (5,2 $\mathrm{g} \mathrm{kg}^{-1}$, estádio R9); logo, apesar da grande extração de K pela cultura, a exportação desse nutriente nos aquênios é baixa, o que permite a reciclagem do $\mathrm{K}$ acumulado.

Por fim, as concentrações dos nutrientes nos aquênios no estádio R9 foram: $\mathrm{N}, 28,3 \mathrm{~g} \mathrm{~kg}^{-1}$; $\mathrm{P}, 5,3 \mathrm{~g} \mathrm{~kg}^{-1} ; \quad \mathrm{K}, 5,2 \mathrm{~g} \mathrm{~kg}^{-1} ; \quad \mathrm{Ca}, 0,9 \mathrm{~g} \mathrm{~kg}^{-1}$;

\footnotetext{
(4) Índice de Colheita Aparente: é a razão entre a massa de grãos e a massa total da parte aérea (incluindo a massa de grãos).
}

$\mathrm{Mg}, 2,9 \mathrm{~g} \mathrm{~kg}^{-1}$; e S, 2,1 $\mathrm{g} \mathrm{kg}^{-1}$ (Quadro 2), resultando assim na seguinte ordem: $\mathrm{N} \gg>>\mathrm{P}=\mathrm{K}>\mathrm{Mg}=\mathrm{S}>$ Ca. Além disso, ao se considerarem as concentrações nos aquênios e nos restos culturais (somatório de folhas, pecíolos, caule e capítulo), no estádio R9 (Quadro 2), foi possível estimar a percentagem de exportação dos nutrientes, ou seja, a relação entre a concentração nos aquênios e a concentração na matéria seca total. Assim, os valores calculados para a exportação foram: N, $42 \%$;, $64 \%$; K, 4,7 \%; Ca, $1,0 \% ; \mathrm{Mg}, 9,6 \%$; e S, 11,5\%. Esses resultados foram inferiores aos apresentados por Castro \& Oliveira (2005), sendo as maiores diferenças observadas para o $\mathrm{Mg}$ e para o $\mathrm{S}$.

\section{Acúmulo de N, P e K}

As marchas de absorção e acúmulo de N, P e K, assim como a distribuição percentual desses nutrientes nas partes das plantas, podem ser visualizadas na figura 2. Os parâmetros do modelo ajustado, por sua vez, estão descritos no quadro 3. Assim como na produção de matéria seca, observa-se que até os 28 DAE o acúmulo de $\mathrm{N}$ e de $\mathrm{P}$ é pequeno (Figura 2a,c); aproximadamente $75 \%$ da quantidade acumulada desses nutrientes até então estava alocada nas folhas (Figura 2b,d).

A partir dos $28 \mathrm{DAE}$, a taxa de acúmulo de $\mathrm{N}$ e $\mathrm{P}$ aumenta de forma acentuada, atingindo o ponto de máxima aos 85 dias, para ambos os nutrientes (Quadro 3). O valor correspondente ao máximo acúmulo, considerando o somatório de folhas, pecíolos, caule, capítulo e aquênios, foi de $3.751,17 \mathrm{mg} / \mathrm{planta}$ para o $\mathrm{N}$ e de 605,45 mg/planta para o $\mathrm{P}$ (Quadro 3), correspondendo à extração de $150 \mathrm{~kg} \mathrm{ha}^{-1}$ de $\mathrm{N}$ e de $24 \mathrm{~kg} \mathrm{ha}^{-1}$ de $\mathrm{P}\left(55 \mathrm{~kg} \mathrm{ha}^{-1}\right.$ de $\left.\mathrm{P}_{2} \mathrm{O}_{5}\right)$.

O ponto de inflexão, determinado a partir do modelo ajustado, ocorreu aos $57 \mathrm{DAE}$ (estádio R3) para o $\mathrm{Ne}$ aos 62 DAE (estádio R4) para o P (Quadro 3); a taxa de acúmulo diário de $\mathrm{N}$ e de $\mathrm{P}$, considerando a média entre os estádios R1 (42 DAE) e R8 (85 DAE), foi de $61 \mathrm{mg} / \mathrm{planta}$ dia para o $\mathrm{N}$ e de $11,3 \mathrm{mg} / \mathrm{planta}$ dia para o $\mathrm{P}$. 
Quadro 2. Concentração de nitrogênio, fósforo, potássio, cálcio, magnésio e enxofre nas diferentes partes da planta, em função das épocas de amostragem

\begin{tabular}{|c|c|c|c|c|c|c|}
\hline Coleta/estádio & $\mathbf{N}$ & $\mathbf{P}$ & $\mathbf{K}$ & $\mathbf{C a}$ & Mg & $\mathrm{S}$ \\
\hline & \multicolumn{6}{|c|}{$-\mathrm{g} \mathrm{kg}^{-1}$} \\
\hline & \multicolumn{6}{|c|}{ Folhas } \\
\hline 14 DAE (V2) & 47,5 & 4,1 & 71,2 & 20,4 & 6,5 & 5,6 \\
\hline 28 DAE (V16) & 49,7 & 3,8 & 38,5 & 22,0 & 7,3 & 5,1 \\
\hline 42 DAE (R1) & 48,7 & 4,2 & 47,9 & 29,3 & 8,8 & 6,4 \\
\hline 56 DAE ( R3) & 46,5 & 3,8 & 33,4 & 23,8 & 7,5 & 5,5 \\
\hline 70 DAE (R6) & 39,9 & 4,6 & 54,8 & 35,9 & 9,5 & 7,4 \\
\hline 84 DAE (R7) & 30,7 & 2,5 & 28,1 & 28,3 & 7,0 & 5,4 \\
\hline \multirow[t]{2}{*}{98 DAE (R9) } & 15,5 & 1,7 & 21,2 & 43,2 & 8,7 & 6,0 \\
\hline & \multicolumn{6}{|c|}{ Pecíolos } \\
\hline 14 DAE (V2) & 19,8 & 0,6 & 23,0 & 5,2 & 2,3 & 1,6 \\
\hline $28 \mathrm{DAE}(\mathrm{V} 16)$ & 15,9 & 1,9 & 86,2 & 14,9 & 6,5 & 2,6 \\
\hline 42 DAE (R1) & 13,3 & 1,9 & 117,5 & 17,4 & 6,5 & 3,4 \\
\hline 56 DAE (R3) & 10,7 & 2,3 & 64,6 & 20,8 & 7,3 & 3,4 \\
\hline 70 DAE (R6) & 9,6 & 1,9 & 130,0 & 28,8 & 9,5 & 4,9 \\
\hline 84 DAE (R7) & 6,7 & 1,1 & 42,9 & 18,2 & 7,5 & 4,2 \\
\hline \multirow[t]{2}{*}{98 DAE (R9) } & 4,8 & 0,8 & 23,7 & 24,8 & 11,5 & 5,8 \\
\hline & \multicolumn{6}{|c|}{ Caule } \\
\hline 14 DAE (V2) & 21,8 & 2,4 & 104,1 & 11,9 & 6,3 & 4,3 \\
\hline $28 \mathrm{DAE}$ (V16) & 14,7 & 2,1 & 71,5 & 8,7 & 5,3 & 2,5 \\
\hline $42 \mathrm{DAE}(\mathrm{R} 1)$ & 14,2 & 2,2 & 93,3 & 8,6 & 4,8 & 2,4 \\
\hline 56 DAE (R3) & 12,8 & 2,3 & 57,1 & 8,5 & 5,2 & 2,1 \\
\hline 70 DAE (R6) & 7,7 & 1,6 & 51,9 & 7,7 & 4,1 & 1,5 \\
\hline 84 DAE (R7) & 4,2 & 0,5 & 24,4 & 5,4 & 3,1 & 0,9 \\
\hline \multirow[t]{2}{*}{98 DAE (R9) } & 3,3 & 0,2 & 20,3 & 6,6 & 3,4 & 0,9 \\
\hline & \multicolumn{6}{|c|}{ Capítulo } \\
\hline 42 DAE (R1) & 35,5 & 7,3 & 31,3 & 15,6 & 3,4 & 4,1 \\
\hline 56 DAE (R3) & 34,2 & 6,1 & 23,4 & 17,1 & 3,6 & 4,0 \\
\hline 70 DAE (R6) & 16,7 & 5,8 & 27,5 & 17,6 & 5,6 & 4,0 \\
\hline 84 DAE (R7) & 12,4 & 2,6 & 24,2 & 11,6 & 3,5 & 2,8 \\
\hline \multirow[t]{2}{*}{98 DAE (R9) } & 11,9 & 1,4 & 39,4 & 13,5 & 3,7 & 3,5 \\
\hline & \multicolumn{6}{|c|}{ Aquênios } \\
\hline 70 DAE (R6) & 26,9 & 4,2 & 15,7 & 3,4 & 1,9 & 2,6 \\
\hline 84 DAE (R7) & 26,7 & 5,6 & 8,5 & 1,4 & 2,8 & 2,4 \\
\hline 98 DAE (R9) & 28,3 & 5,3 & 5,2 & 0,9 & 2,9 & 2,1 \\
\hline
\end{tabular}

(1) Média de quatro repetições.

A partir do estádio R1 (42 DAE), foi possível observar o início da redistribuição de $\mathrm{P}$ para as estruturas reprodutivas em formação (botão floral), ao passo que, para o $\mathrm{N}$, a redistribuição pode ser observada do estádio R3 (56 DAE) em diante. Em ambos os casos, a folha foi a principal fonte de redistribuição de $\mathrm{N} \mathrm{e} \mathrm{P,}$ apresentando na maturação fisiológica (R9) menos de $20 \%$ de acúmulo relativo desses nutrientes (Figura 2b,d), sendo essa retranslocação direcionada principalmente para os aquênios, assim como registrado por Gachon (1972) e Sfredo et al. (1984).

$\mathrm{O} \mathrm{K}$, por sua vez, foi o nutriente exigido em maiores quantidades pelo girassol, tendo em vista que o valor do ponto de máximo acúmulo de $\mathrm{K}$ foi de $7.148,76 \mathrm{mg} /$ planta (Quadro 3), aos 74 DAE - estádio R7, ou seja, uma extração correspondente a $346 \mathrm{~kg} \mathrm{ha}^{-1}$ de $\mathrm{K}_{2} \mathrm{O}$. O ponto de inflexão para o acúmulo de K nas folhas e $\mathrm{K}$ total ocorreu, em ambos os casos, no está- dio R3 (52 e 53 DAE, respectivamente), não diferindo do que foi observado para o $\mathrm{N}$ e para o $\mathrm{P}$.

Além da maior exigência, a distribuição do $\mathrm{K}$ absorvido pelo girassol (Figura 2f) não segue o mesmo padrão verificado para $\mathrm{N}$ e para o $\mathrm{P}$, pois, durante as fases vegetativas e também durante o início da fase reprodutiva (estádio $\mathrm{R} 1$ ), aproximadamente 50 a $60 \%$ do K estava alocado nos caules e não nas folhas. Além disso, a redistribuição do nutriente ocorre preferencialmente para o capítulo e não para os aquênios, sendo também o caule o principal órgão-fonte para essa redistribuição. Sfredo et al. (1984) também observaram que o $\mathrm{K}$ no caule apresentou o maior acúmulo em relação aos demais órgãos da planta. Nesse sentido, Putt (1997) relatou que, devido a esse alto acúmulo de K no caule do girassol, a Rússia, no início do século $\mathrm{XX}$, produziu e exportou $\mathrm{K}$ utilizando caule de girassol como fonte de nutriente. 
(a)

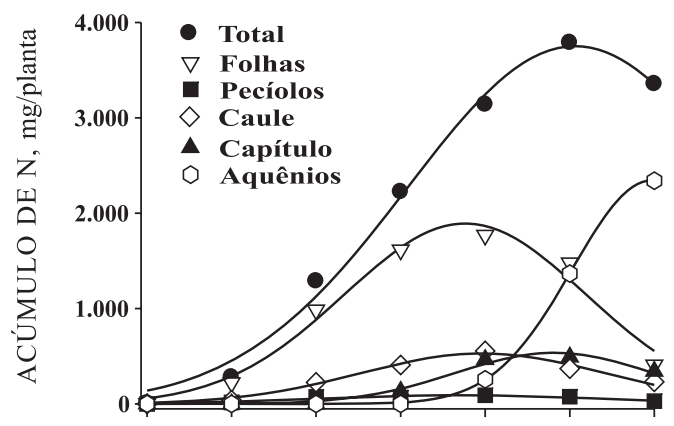

(c)

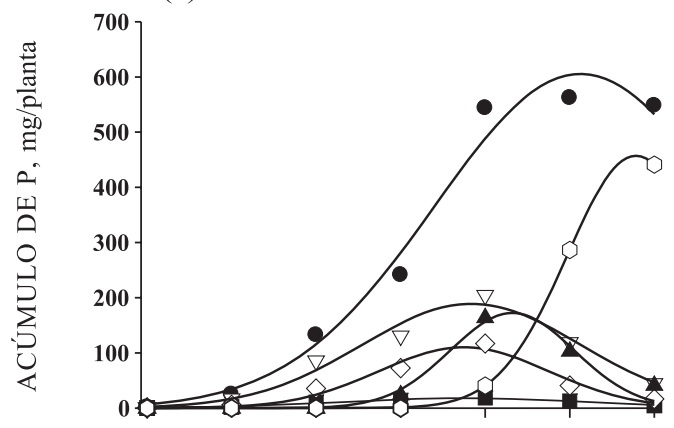

(e)

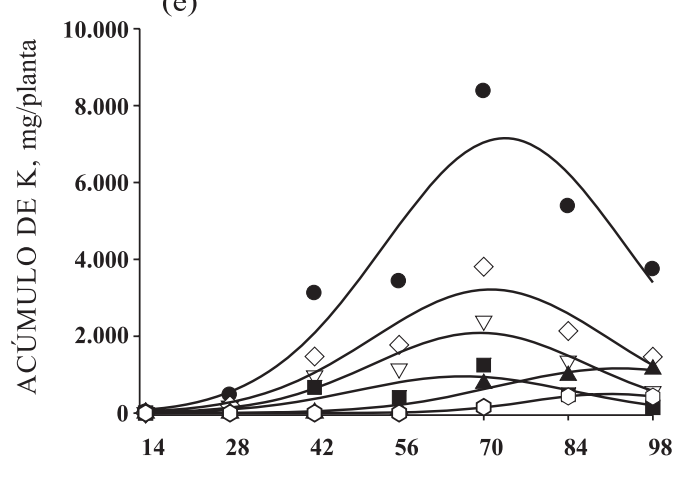

(b) $\begin{aligned} & \text { Folha } \\ & \text { Pecíolo }\end{aligned}$ Caule $\rightleftharpoons$ Capítulo

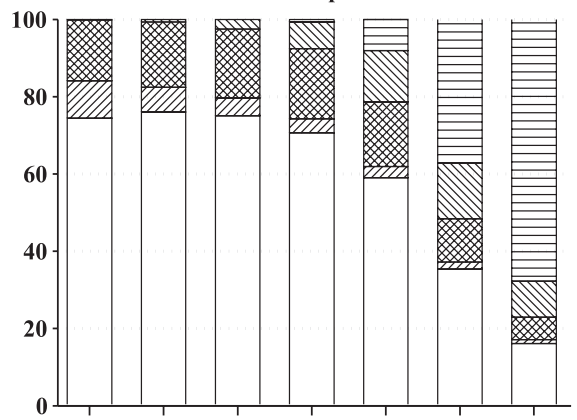

(d)

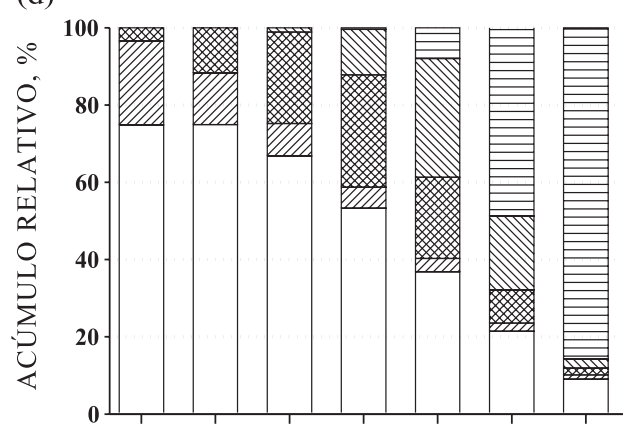

(f)

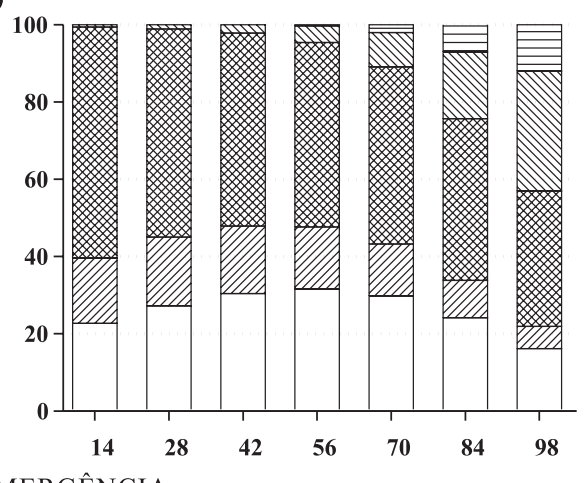

Figura 2. Marcha de absorção dos macronutrientes primários e respectivo acúmulo relativo nas partes das plantas. (a) e (b): nitrogênio; (c) e (d): fósforo; (e) e (f): potássio.

Dessa forma, pode-se dizer que, apesar da alta exigência da cultura por K, aproximadamente 90$95 \%$ da quantidade absorvida é passível de retornar ao solo com a mineralização dos restos culturais; assim, o cultivo do girassol pode ser interessante para a reciclagem de K. Além disso, essa alta extração pode também estar relacionada ao alto teor de $\mathrm{K}$ no solo $\left(0,45 \mathrm{cmol}_{\mathrm{c}} \mathrm{dm}^{-3}\right)$, possibilitando o consumo de luxo do nutriente.

Portanto, considerando a dinâmica do N e do K no solo, seria interessante realizar a adubação de cobertura com esses nutrientes aproximadamente aos 30-35 DAE, para que haja adequada disponibilidade deles durante a fase crítica de acúmulo, principalmente em solos com maior probabilidade de perdas por lixiviação.

\section{Acúmulo de Ca, Mg e S}

As curvas de acúmulo de $\mathrm{Ca}$, de $\mathrm{Mg}$ e de $\mathrm{S}$ apresentaram comportamento muito semelhante, pois, nos três casos, o ponto de inflexão foi verificado aos 58-59 DAE (estádio R4), e o ponto de máxima, aos 80-82 DAE, no estádio R7 (Quadro 4). Isso indica que o acúmulo desses nutrientes segue a mesma tendência, variando somente a magnitude da quantidade acumulada, que foi maior para o $\mathrm{Ca}(2.903,18 \mathrm{mg} /$ planta), seguido pelo $\mathrm{Mg}(1.047,09 \mathrm{mg} /$ planta) e pelo $\mathrm{S}\left(605,33 \mathrm{mg} /\right.$ planta), extraindo $116 \mathrm{~kg} \mathrm{ha}^{-1} \mathrm{de} \mathrm{Ca}$, $42 \mathrm{~kg} \mathrm{ha}^{-1}$ de Mg e somente $24 \mathrm{~kg} \mathrm{ha}^{-1}$ de S.

Avaliando a distribuição dos nutrientes na planta, verificou-se que até o estádio R3 (56 DAE) aproximadamente $60-70 \%$ da quantidade acumulada 
Quadro 3. Estimativas dos parâmetros dos modelos ajustados para o acúmulo de nitrogênio, fósforo e potássio em função do tempo e os respectivos valores do ponto de inflexão (PI)

\begin{tabular}{|c|c|c|c|c|c|c|}
\hline \multirow{2}{*}{ Parte da planta } & \multicolumn{4}{|c|}{ Estimativa dos parâmetros do modelo ajustado(2) } & \multirow{2}{*}{$\begin{array}{c}P I \\
\left(X_{0}-b\right)\end{array}$} & \multirow{2}{*}{$\mathbf{R}^{2}$} \\
\hline & a & $\mathbf{X}_{\mathbf{0}}$ & & $\bar{b}$ & & \\
\hline & $\mathrm{mg} / \mathrm{planta}$ & \multicolumn{3}{|c|}{ _ dias após a emergência __ } & & \\
\hline Folha & $1891,79^{* *}$ & $66,69^{* *}$ & Nitrogênio & $20,01^{* *}$ & 47 & 0,97 \\
\hline Pecíolo & $91,16^{* *}$ & $65,90^{* *}$ & & $23,33^{\text {** }}$ & 43 & 0,88 \\
\hline Caule & $529,28^{* *}$ & $69,65^{* *}$ & & $20,33^{* *}$ & 49 & 0,98 \\
\hline Capítulo & $536,91^{* *}$ & $81,46^{* *}$ & & $16,36^{* *}$ & 65 & 0,98 \\
\hline Aquênios & $2342,89^{* *}$ & $97,58^{* *}$ & & $13,09^{* *}$ & 85 & 0,99 \\
\hline $\operatorname{Total}^{(1)}$ & $3751,17^{* *}$ & $84,89^{* *}$ & & $27,67^{* *}$ & 57 & 0,99 \\
\hline Folha & $188,98^{* *}$ & $67,73^{* *}$ & \multirow[t]{6}{*}{ Fósforo } & $18,08^{* *}$ & 50 & 0,96 \\
\hline Pecíolo & $17,84^{* *}$ & $66,69^{\text {** }}$ & & $20,53^{* *}$ & 16 & 0,97 \\
\hline Caule & $110,17^{* *}$ & $66,45^{* *}$ & & $14,07^{* *}$ & 52 & 0,95 \\
\hline Capítulo & $172,36^{* *}$ & $74,50^{* *}$ & & $10,26^{* *}$ & 64 & 0,96 \\
\hline Aquênios & $457,18^{* *}$ & $94,96^{* *}$ & & $11,34^{* *}$ & 83 & 0,99 \\
\hline Total & $605,45^{\text {** }}$ & $85,79^{* *}$ & & $24,08^{* *}$ & 62 & 0,98 \\
\hline Folha & $2084,43^{* *}$ & $69,40^{* *}$ & \multirow[t]{6}{*}{ Potássio } & $17,83^{* *}$ & 52 & 0,90 \\
\hline Pecíolo & $954,20^{*}$ & $66,64^{* *}$ & & $17,88^{*}$ & 49 & 0,68 \\
\hline Caule & $3213,33^{* *}$ & $71,15^{\text {** }}$ & & $19,51^{* *}$ & 52 & 0,88 \\
\hline Capítulo & $1159,30^{* *}$ & $92,08^{* *}$ & & $19,69^{* *}$ & 72 & 0,97 \\
\hline Aquênios & $496,76^{* *}$ & $90,73^{* *}$ & & $13,21^{* *}$ & 78 & 0,99 \\
\hline Total & $7148,76^{* *}$ & $73,50^{\text {** }}$ & & $20,09^{* *}$ & 53 & 0,88 \\
\hline
\end{tabular}

(1) Somatório da MS das folhas, dos pecíolos, do caule, do capítulo e dos aquênios. ${ }^{(2)}$ a: corresponde ao valor de máximo acúmulo; $\mathrm{x}_{0}$ : corresponde ao valor de $\mathrm{x}$, em DAE, que proporciona o máximo em $\hat{\mathrm{y}}$; b: corresponde à amplitude no valor de $\mathrm{x}$, em DAE, entre o ponto de inflexão e o ponto de máximo. ${ }^{* * * ; *}$ : significativo, respectivamente, a 1 e $5 \%$ pelo teste t.

Quadro 4. Estimativas dos parâmetros dos modelos ajustados para o acúmulo de cálcio, magnésio e enxofre em função do tempo e os respectivos valores do ponto de inflexão (PI)

\begin{tabular}{|c|c|c|c|c|c|}
\hline \multirow[b]{2}{*}{ Parte da planta } & \multicolumn{3}{|c|}{ Estimativa dos parâmetros do modelo ajustado (2) } & \multirow[b]{2}{*}{ P.I. } & \multirow[b]{2}{*}{$\mathbf{R}^{2}$} \\
\hline & $\mathbf{a}$ & $\mathbf{X}_{0}$ & b & & \\
\hline & $\mathrm{mg} /$ planta & \multicolumn{2}{|c|}{ — dias após a emergência } & & \\
\hline Folha & $1544,44^{* *}$ & $78,01^{\text {** }}$ & $23,58^{* *}$ & 54 & 0,96 \\
\hline Pecíolo & $248,78^{* *}$ & $75,36^{* *}$ & $21,42^{* *}$ & 54 & 0,94 \\
\hline Caule & $549,52^{* *}$ & $81,90^{* *}$ & $23,70^{* *}$ & 58 & 0,96 \\
\hline Capítulo & $536,46^{* *}$ & $82,81^{* *}$ & $16,60^{* *}$ & 66 & 0,93 \\
\hline Aquênios & $80,94^{* *}$ & $90,89^{* *}$ & $14,87^{* *}$ & 76 & 0,99 \\
\hline Total $^{(1)}$ & $2903,18^{* *}$ & $80,08^{* *}$ & $22,29^{\text {** }}$ & 58 & 0,96 \\
\hline Folha & \multicolumn{4}{|c|}{ Magnésio } & 0,98 \\
\hline Pecíolo & $90,05^{* *}$ & $79,74^{\text {** }}$ & $24,68^{* *}$ & 55 & 0,97 \\
\hline Caule & $301,48^{* *}$ & $80,31^{* *}$ & $23,22^{* *}$ & 57 & 0,98 \\
\hline Capítulo & $165,87^{* *}$ & $81,36^{\text {** }}$ & $15,43^{* *}$ & 66 & 0,92 \\
\hline Aquênios & $246,79^{* *}$ & $96,09^{* *}$ & $11,48^{* *}$ & 85 & 0,99 \\
\hline Total & \multirow{2}{*}{\multicolumn{4}{|c|}{ Enxofre }} & 0,98 \\
\hline Folha & $309,39^{* *}$ & $73,16^{\text {** }}$ & $21,12^{* *}$ & & 0,98 \\
\hline Pecíolo & $48,12^{* *}$ & $80,33^{* *}$ & $23,54^{\text {** }}$ & 57 & 0,96 \\
\hline Caule & $101,87^{* *}$ & $74,56^{* *}$ & $22,17^{* *}$ & 52 & 0,96 \\
\hline Capítulo & $126,49^{* *}$ & $84,47^{* k}$ & $17,36^{* *}$ & 67 & 0,94 \\
\hline Aquênios & $181,81^{* *}$ & $95,15^{* *}$ & $12,54^{* *}$ & 83 & 0,99 \\
\hline Total & $655,33^{* *}$ & $82,36^{\text {** }}$ & $23,49^{* *}$ & 59 & 0,98 \\
\hline
\end{tabular}

(1) Somatório da MS das folhas, dos pecíolos, do caule, do capítulo e dos aquênios. ${ }^{(2)}$ a: corresponde ao valor de máximo acúmulo; $\mathrm{x}_{0}$ : corresponde ao valor de $\mathrm{x}$, em DAE, que proporciona o máximo em $\hat{\mathrm{y}}$; b: corresponde à amplitude no valor de $\mathrm{x}$, em DAE, entre o ponto de inflexão e o ponto de máximo. ${ }^{* * *} ;$ : significativo, respectivamente, a 1 e $5 \%$ pelo teste t. 
dos três nutrientes estava alocada nas folhas (Figura 3). Entretanto, durante a fase reprodutiva as folhas consistiram na principal fonte de redistribuição de $\mathrm{Mg}$ somente, ao passo que, para o $\mathrm{S}$, embora pequena, a redistribuição ocorreu a partir do caule (Quadro 2). No caso do $\mathrm{Ca}$, a redistribuição para os aquênios foi muito baixa, resultando em apenas $2 \%$ do total acumulado ao final do ciclo. Esses resultados estão de acordo com os obtidos por Gachon (1972).

(a)

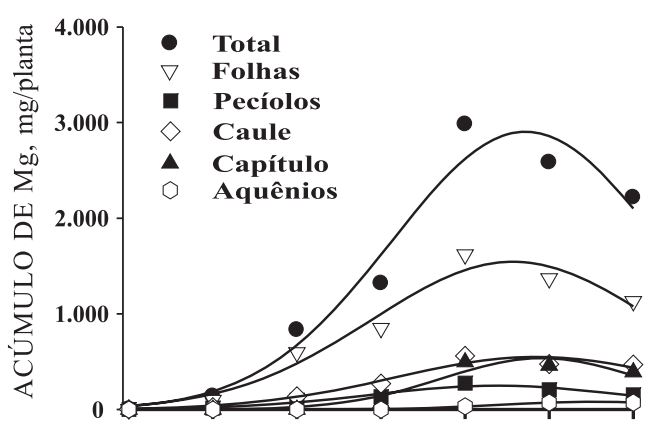

(c)

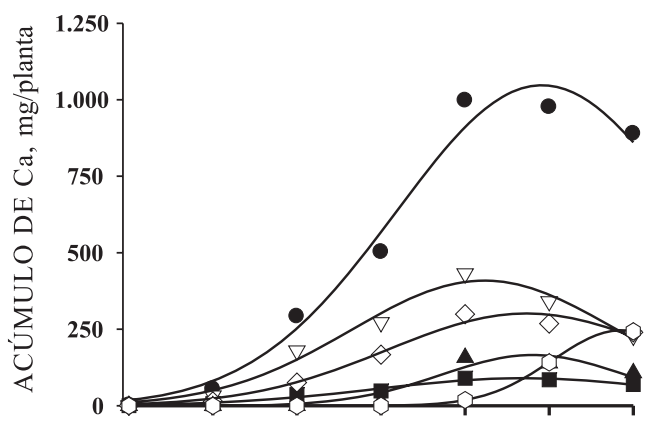

(e)

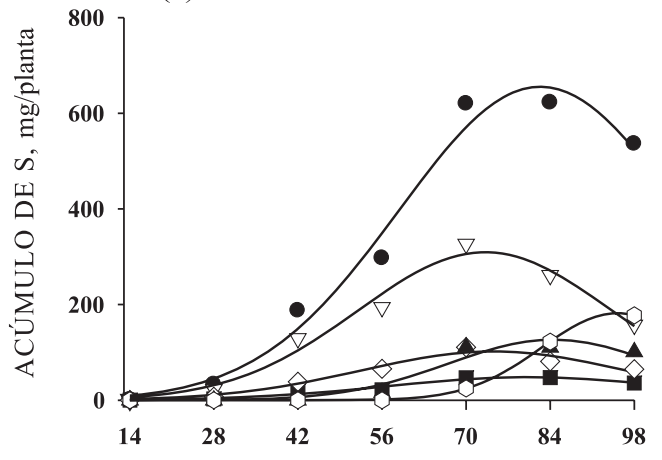

deve ser dada à manutenção da adequada disponibilidade de $\mathrm{N}, \mathrm{K}$ e $\mathrm{Ca}$, devido à alta demanda da cultura por esses nutrientes.

2. O K é o nutriente absorvido em maiores quantidades, porém a redistribução para os aquênios é baixa, indicando que grande parte do K acumulado pode retornar ao solo com a decomposição dos restos culturais. A ordem de exportação, por sua vez, foi a seguinte: $\mathrm{N}>\mathrm{P}=\mathrm{K}>\mathrm{Mg}=\mathrm{S}>\mathrm{Ca}$.
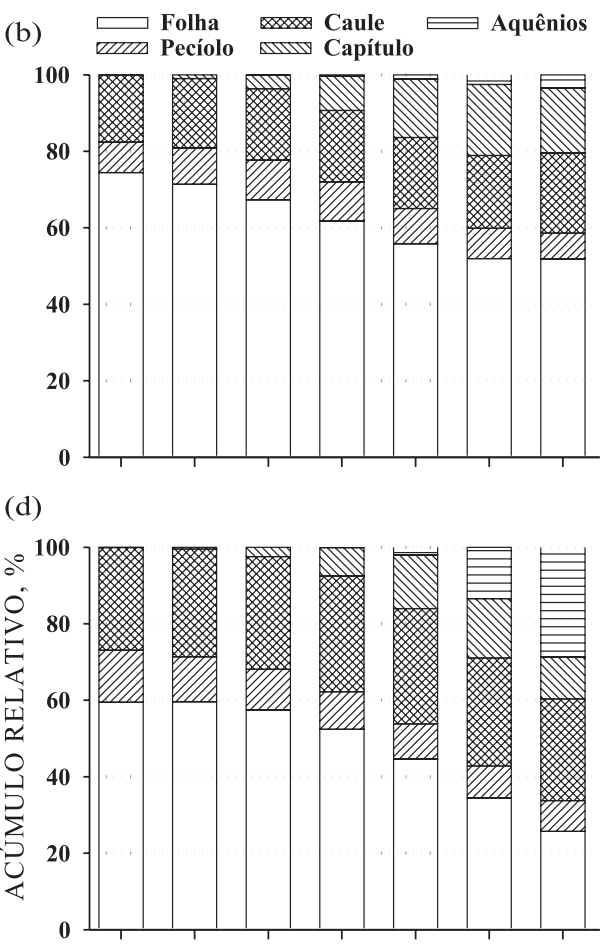

(f)

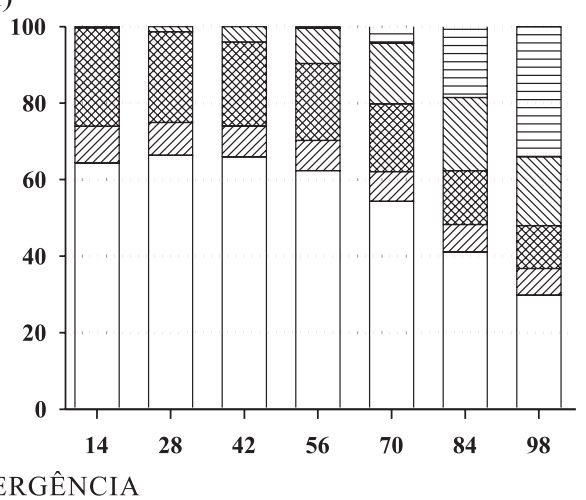

Figura 3. Marcha de absorção dos macronutrientes secundários e respectivo acúmulo relativo nas partes das plantas. (a) e (b): cálcio; (c) e (d): magnésio; (d) e (f): enxofre.

\section{CONCLUSÕES}

1. A ordem de extração de macronutrientes pelas plantas de girassol (híbrido BRS 191) foi a seguinte: $\mathrm{K}>\mathrm{N}>\mathrm{Ca}>\mathrm{Mg}>\mathrm{P}=\mathrm{S}$. Assim, atenção especial
3. O ponto de inflexão nas curvas de acúmulo total ocorreu entre 53 e 62 DAE, ou seja, entre os estádios R3 e R4. A definição do ponto de inflexão é importante para o manejo da nutricional da cultura, pois é em torno desse período que se deve realizar a amostragem para fins de diagnose foliar. 
4. No caso de nutrientes que são mais suscetíveis às perdas, o parcelamento deve ser realizado até o início da fase de acentuado acúmulo de nutrientes (3040 DAE), visando manter a disponibilidade em condições adequadas para o desenvolvimento das plantas, e até que as concentrações na planta sejam suficientes para possibilitar a redistribuição durante a formação dos aquênios.

\section{AGRADECIMENTOS}

Ao Conselho Nacional de Desenvolvimento Científico e Tecnológico (CNPq), pelo apoio financeiro; e à Embrapa Soja, pelo incentivo à pesquisa.

\section{LITERATURA CITADA}

CASTRO, C.; CASTIGLIONI, V.B.R.; BALLA, A.; LEITE, R.M.V.B.C.; MELLO, H.C.; GUEDES, L.C.A. \& FARIAS, J.R. A cultura do girassol. Londrina, Embrapa-CNPSo, 1996. 38p. (Embrapa, CNPSo, Circular Técnica, 13)

CASTRO, C. \& FARIAS, J.R.B. Ecofisiologia do girassol. In: LEITE, R.M.V.B.C.; BRIGHENTI, A.M. \& CASTRO, C. Girassol no Brasil. Londrina, 2005. p.164-218.

CASTRO, C. \& OLIVEIRA, F.A. Nutrição e adubação do girassol. In: LEITE, R.M.V.B.C.; BRIGHENTI, A.M. \& CASTRO, C. Girassol no Brasil. Londrina, 2005. p.317373.

CONAB. Sexto levantamento: safra 2004/2005. Disponível em: $<$ http://www.conab.gov.br> Acesso em: 20 dez. de 2008.

CONNOR, J.D. \& HALL, A.J. Sunflower physiology. In: SCHNEIDER, A.A., ed. Sunflower technology and production. Madison, ASA/CSSA/SSSA, 1997. p.113-181. (Series of Monograph, 35)

DALL'AGNOL, A.; VIEIRA, O.V. \& LEITE, R.M.V.B.C. Origem e histórico do girassol. In: LEITE, R.M.V.B.C.; BRIGHENTI, A.M. \& CASTRO, C. Girassol no Brasil. Londrina, 2005. p.1-14.
EMPRESA BRASILEIRA DE PESQUISA AGROPECUÁRIA EMBRAPA. Manual de análises químicas de solos, plantas e fertilizantes. Brasília, 1999. 370p.

EMPRESA BRASILEIRA DE PESQUISA AGROPECUÁRIA EMBRAPA. Sistema brasileiro de classificação de solos. 2.ed. Rio de Janeiro, Embrapa Solos, 2006. 306p.

GACHON, I. La cinétique de l'absorption dês éléments nutritifs majeurs chez le tournesol. Ann. Agron., 23:547-566, 1972.

LAZZAROTTO, J.J.; ROESSING, A.C. \& MELLO, H.C. O agronegócio do girassol no mundo e no Brasil. In: LEITE, R.M.V.B.C.; BRIGHENTI, A.M. \& CASTRO, C. Girassol no Brasil. Londrina, 2005. p.15-42.

MANDARINO, J.M.G. Características bioquímicas e nutricionais do óleo e do farelo de girassol. Londrina, Embrapa-CNPSo, 1992. 25p. (Embrapa-CNPSo. Documento 52)

MERRIEN, A. Physiologie du tournesol. Paris, Cetion, 1992. $66 \mathrm{p}$.

MIYAZAWA, M.; PAVAN, M.A. \& BLOCH, M.F. Análise química de tecido vegetal. Londrina, IAPAR, 1992. 17p. (IAPAR, Circular, 74)

PUTT, E.D. Early history of sunflower. In: SCHENEITER, A.A., ed. Sunflower technology and production. Madison, America Society of Agronomy, 1997. p.1-19.

SARRUGE, J.R. \& HAAG, H.P. Análise química em plantas. Piracicaba, ESALQ, 1974. 56p.

SCHNEITER, A.A. \& MILLER, J.F. Description of sunflower growth stages. Crop Sci., 21:901-903, 1981.

SFREDO, G.J.; SARRUGE, J.R. \& HAAG, H.P. Absorção de nutrientes por duas cultivares de girassol (Helianthus annuus, L.), em condições de campo. I. Concentração de macronutrientes. An. ESALQ, 40:1135-1163, 1983a.

SFREDO, G.J.; SARRUGE, J.R. \& HAAG, H.P. Absorção de nutrientes por duas cultivares de girassol (Helianthus annuus, L.), em condições de campo. III. Acúmulo de macronutrientes. An. ESALQ, 40:1189-1217, 1983b.

SFREDO, G.J.; SARRUGE, J.R. \& HAAG, H.P. Girassol: Nutrição mineral e adubação. Londrina, Embrapa-CNPSo. 1984. 36p. (Embrapa-CNPSo. Circular Técnica, 8) 
